\title{
Trends in Cloud Computing
}

\author{
Shreya S. Dadpe, Pratiksha P. Patil, Prof. V. M. Sultanpure \\ Department of Computer Science, Sangameshwar College, Solapur, Maharashtra, India
}

\begin{abstract}
Article Info

Volume 8 Issue 2

Page Number: 402-405

Publication Issue :

March-April-2021

Article History

Accepted : 15 April 2021

Published : 30 April 2021

In today's world cloud computing is widely used in many it industries. Cloud computing is an emerging model of business computing. Cloud computing which is based on internet has the most powerful architecture of computation. Because of the newly in innovative technologies in cloud computing, the number of labs is transformed into cloud named as the virtual labs. It considers a collection of integrated and networked hardware, software and internet infrastructure. Cloud computing is a development of parallel computing, distributed computing, grid computing and virtualisation technologies from cloud computing adoption accept and also focuses on cloud interoperability issues. We also present the popular platforms of cloud computing. In this paper, we explore several cloud computing system providers about their concerns on security and privacy issues. We also present the characteristics and applications of different well-known cloud computing platforms. We also purpose to recognise the challenges and issues of cloud computing. However, security and privacy issues present a strong roadblock for users to adapt into cloud computing systems.
\end{abstract}

Keywords : Cloud computing, SaaS, PaaS, IaaS, architecture, challenges.

\section{INTRODUCTION}

In real world, the word 'cloud' means a collection of water molecules. In cloud computing, the word cloud is also a collection but this collection is of networks. Cloud is a technology which is a symbol to describe web as a space where computing has been preinstalled and exist as a service. The users generally prefer a mediator provider for the service of the internet in cloud computing rather than establish their own physical framework. The user can use the methods of cloud computing infinite times whenever demanded. Data, operating systems, applications, storage and processing power exist on the web ready to be shared. It is the combination and evolution of Virtualization, Utility computing, Software-as-aService (SaaS), Infrastructure-as-a-Service (IaaS) and Platform-as-a-Service (PaaS). The users have to pay only for the services they had used. To users, cloud computing is a Pay-per-Use-On-Demand mode that can easily access shared IT resources through the Internet. Where the IT resources include network, server, storage, application, service and they can be deployed with much easy manner and least management and also interactions with service providers. The workload can be shifted to reduce the 
workload in cloud computing. The load on local computers is not heavy while running an application because a load of service is handled by the networks which forms the cloud. So, the demand of hardware and software at the user side is reduced. Cloud computing can much enhance the availability of IT resources and have many advantages over other computing techniques. Users can use the IT infrastructure with Pay-per-Use-On-Demand mode this would benefit and save the cost to buy the physical resources that may be vacant. All we need to have a web browser like chrome to use cloud computing. There are three services provided by cloud computing that are Software as a Service (SaaS), Platform as a Service $(\mathrm{PaaS})$ and Infrastructure as a Service (IaaS). There are three types of cloud. First one is Public Cloud which can be used by any user. Second one is Private Cloud which is used by selected users. The last one is Hybrid Cloud which is the combination of both private and public cloud.

\section{Components of Cloud Computing}

Components of Cloud Computing are as follows

1. Client Computers: The end user can interact with the cloud using the client computers.

2. Distributed Servers: The servers are distributed among the different places but acts like they as working with each other.

3. Data Centres: Data centres are the compilation of servers.

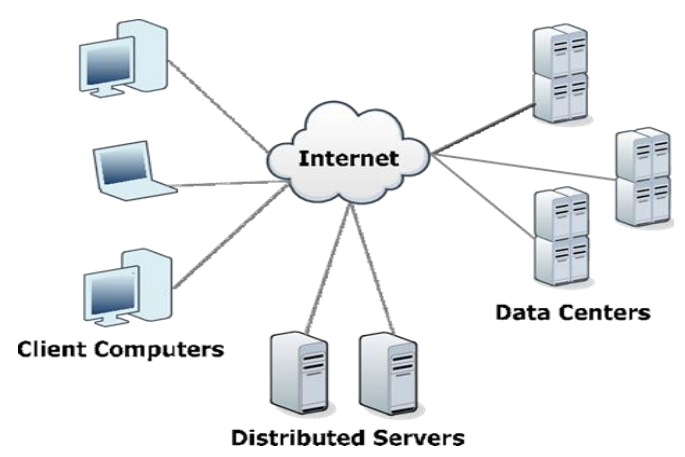

Fig.1. Components

\section{Services of Cloud Computing}

There are four types of services in cloud computing.

\section{Software as a Service (SaaS):}

Cloud users do not have control over the cloud that usually applies to different cloud consumers applications so they are organized in a single logical environment in the SaaS cloud to achieve scale effects optimization in regarding speed, accessibility, recovery and maintenance. The way of carrying application as a service on the internet is known as software as a service (SaaS). The user can simply access software via the internet in place of installing it on his system. The only thing user must have an internet connection and then access to the application is very easy. Cloud users set free their applications in a hosting environment, which can be accessed through networks from different clients. Examples of SaaS contains Microsoft Office 365, Google Mail, Google Docs.

\section{Platform as a Service (PaaS):}

$\mathrm{PaaS}$ is a development platform aiding the complete Software Lifecycle which grant cloud users to establish cloud services and applications directly on the PaaS cloud. A development platform is given to the users as a service in PaaS, on top of which user can deploy their own software and coding. The User has the choice to create his own applications that can run on the provider's framework. The difference between SaaS and PaaS is that SaaS only hosts completed. cloud applications whereas PaaS offers a development platform that hosts both completed and in-progress cloud applications. Product as a service provider gives a predetermined composition of operating system and application server to acquire the management capacity of the applications. There are examples of PaaS like J2EE, Ruby, Google AppEngine. LAMP (Linux, Apache, MySQL, and PHP), etc. 


\section{Infrastructure as a Service (IaaS)}

Cloud users straight uses IT architecture such as processing, storage, networks which given in the IaaS cloud. The users of IaaS cloud access the services of this cloud using WAN (Wide Area Network) just like Internet. A user of this cloud can develop virtual machines by sign in to the IaaS platform. The example of this cloud is Amazon's EC2.

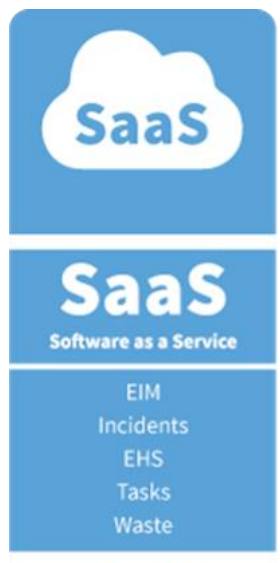

Use It

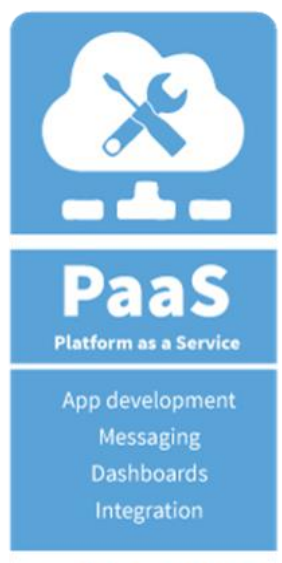

Build with It

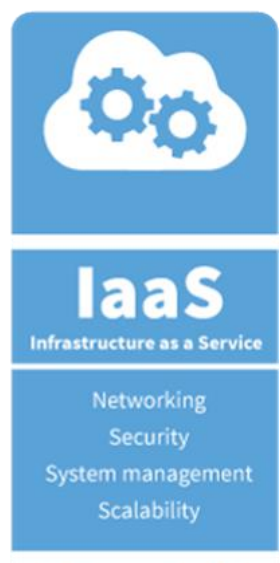

Move to It

\section{Fig.2. Services of Cloud Computing}

\section{Popular Platforms of Cloud Computing}

\section{A. abiCloud:}

abiCloud is a platform which can be used to build, integrate and manage public and private cloud. User can effortlessly and spontaneously deploy and handle the server, storage system, virtual devices, network and applications with help of abiCloud. User can complete deploying a new service by just moving a virtual machine with mouse with the use of abiCloud.

\section{B. Eucalyptus (Elastic Utility Computing Architecture for Linking Your Programs to Useful Systems):}

Eucalyptus is an elastic computer architecture that can be applied to connect the user's programs to the functionable systems. It is an open-source framework using clusters implementation of elastic, utility, cloud computing based on a service level rules that allow users lease network for computing capability.

\section{Nimbus:}

Nimbus allows users lease negligible resources and construct the required computing environment through the deployment of virtual machines. Once Nimbus is installed on a cluster, it allows a deployment and configuration of virtual machines on remote resources. It is totally free and open source because it is written in Python and Java.

\section{Applications}

There are few applications of cloud computing:

1. Infinite capability for users to use the internet which is provided by the cloud.

2. It provides responsible and secure data storage centre.

3. Cloud computing is easy to use. Cloud does not need high quality equipment for the user.

4. Cloud computing can carry data sharing among distinct equipments.

\section{Future of Cloud Computing}

\section{A. Increase Storage Capacity:}

In today's world, data is generating in a high volume and it is difficult to store it with security. Most of the companies require a place where they can securely store their data. Cloud providers will provide more data centres at a lower price as there is a large competition between them.

\section{B. Enhanced Performance of Internet:}

The quality of the internet can be increased With the help of the Internet of Things. We can store data in the cloud, for further analyze \& provide enhanced performance with the help of the IoT and Cloud Computing.

\section{Data Shows How Future Changes:}

The cloud computing market is growing at 22.8 percent. It will exceed $\$ 127.5$ after 2018. By 2018, 62\% 
of all CRM software will be cloud-based. Moreover, $30 \%$ of all application spending is for software as a service-based application.

\section{Security:}

The small companies which are providing cloud services may or may not provide proper security to the data. The data which are stored in the cloud is secure but not fully.

\section{CONCLUSION}

This paper discussed popular platforms of cloud computing. It also addressed components and services of cloud computing in detail. In this paper, we also present popular platforms of cloud computing. We also describe future of cloud computing. Cloud Computing initiatives could affect the enterprises within two to three years as it has the potential to significantly change IT.

\section{ACKNOWLEDGMENT}

Behind every successful work, there are efforts of many people, directly or in-directly. I take this opportunity to thank all those who helped me during this endeavour. First of all, I would like to express my sincere, profound sense of gratitude towards my guide Prof. V. M. Sultanpure who was always there with me to show me the way whenever I was in need. I am privileged by being associated with her. Her constant support and inspiration gave me the initial thrust required to excel further. I am thankful to Ms. J. J. Kadadi, Director of Sangameshwar College, Solapur for her zealous and encouraging attitude. I am thankful to Prof. N. B. Kodam, HOD of Department of computer Science, Sangameshwar College, Solapur for their all-round support. I devote this work to my family who are behind success of this work. Without their support, this work would have been impossible.

\section{REFERENCES}

[1]. S. Zhang, S. F. Zhang, X. B. Chen, and X. Z. Huo, "Cloud Computing Research and Development
Trend," In Proceedings of the 2010 Second International Conference on Future Networks (ICFN '10). IEEE Computer Society, Washington, DC, USA, pp. 93-97. DOI=10.1109/ICFN.2010. 58.

[2]. J. J. Peng, X. J. Zhang, Z. Lei, B. F. Zhang, W. Zhang, and Q. Li, "Comparison of Several Cloud Computing Platforms," 2009 Second International Symposium on Information Science and Engineering (ISISE '09). IEEE Computer Society, Washington, DC, USA, pp. 23-27, DOI=10.1109/ISISE.2009.94.

[3]. S. Zhang, S. F. Zhang, X. B. Chen, and X. Z. Huo, "The Comparison between Cloud Computing and Grid Computing," 2010 International Conference on Computer Application and System Modeling (ICCASM), pp. V11-72 - V11-75, DOI= 22-24 Oct. 2010.

[4]. M. Alabbadi, "Cloud Computing for Education and Learning: Education and Learning as a Service (ELaaS)," 2011 14th International Conference on Interactive Collaborative Learning (ICL), pp. 589 594, DOI=21-23 Sept. 2011.

[5]. P. Kalagiakos "Cloud Computing Learning," 2011 5th International Conference on Application of Information and Communication Technologies (AICT), Baku pp. 1 - 4, DOI=12-14 Oct. 2011.

[6]. P. Mell and T. Grance, "Draft nist working definition of cloud computing - vol. 21, Aug 2009, 2009.

[7]. W. Dawoud, I. Takouna, and C. Meinel, "Infrastructure as a Service Security: Challenges and Solutions," 2010 7th International Conference on Informatics and System, pp. 1-8, March 2010.

\section{Cite this article as :}

Shreya S. Dadpe, Pratiksha P. Patil, Prof. V. M. Sultanpure, "Trends in Cloud Computing", International Journal of Scientific Research in Science, Engineering and Technology (IJSRSET), Online ISSN : 2394-4099, Print ISSN : 2395-1990, Volume 8 Issue 2, pp. 402-405, MarchApril 2021. Available at doi : https://doi.org/10.32628/IJSRSET218295 Journal URL : https://ijsrset.com/IJSRSET218295 